\title{
Evaluating the Quality of Health Care Services in the Hashemite Kingdom of Jordan
}

\author{
Suleiman S. Abu-Kharmeh (Associate Professor) \\ Faculty of Planning and Management \\ Balqa Applied University, Jordan
}

Tel: 962-795-592-761 E-mail: dr_kharmeh@yahoo.com

\author{
Received: October 15, 2011 \\ Accepted: November 29, $2011 \quad$ Published: February 16, 2012 \\ doi:10.5539/ijbm.v7n4p195 \\ URL: http://dx.doi.org/10.5539/ijbm.v7n4p195
}

\begin{abstract}
The purpose of this study is to evaluate the quality of health care services provided in the Hashemite Kingdom of Jordan. An instrument of the quality of health service was developed in order to achieve the purpose of this study. The instrument consisted of (31) items, distributed on five dimensions: tangibles, reliability, responsiveness, assurance and empathy. The indications of validity and reliability were confirmed.

The sample of this study consisted of (556) patients admitted in hospitals located in three regions within Jordan, north, center and south. The study was conducted in July 2010 and relied on analytical descriptive approach. Adequate statistical methods were performed in order to answer the study questions and test hypotheses.

The results showed that the level of quality health services provided to patients of Jordanian hospital was moderate, and the dimensions of the service quality were also moderate except responsiveness and assurance variables that were high. The responsiveness came at the first rank while the reliability ranked lastly. There were no significant differences in the level of quality health services provided to patients of Jordanian hospital regarding social status variable. Furthermore, the results indicated significant differences in the level of quality health services provided to patients of Jordanian hospitals regarding variables of gender, age and region.
\end{abstract}

Keywords: Quality, Service quality, Health services, Health sector of Jordan, The regional planning

\section{Introduction}

Regional planning in Jordan's health system set a regional standard since Jordan has made good progress with reforming the heath services. Despite of hard conditions Jordan encountered, economic growth improved and comprehensive health prosperity occurred during the last 40 years accomplished with great achievements in the medical field.

The first act of law to regulate health services in Jordan was enforced in 1926. The MOH was first established in 1950 whereas the first Jordanian medical association was founded in 1944. Major developments in the health sector have since taken place in a country where the total expenditure on health services in 2003 reached about JD 727 million where 10.4\% of the GDP and health care expenditure per capita reached to 133 JD. In 2006, the average annual population growth rate was $2.3 \%$, infant mortality rate was $22 / 1000$ live births, the maternal mortality ratio was $41 / 100.000$ live births, the budget for $\mathrm{MOH}$ was $6.1 \%$ of the total general budget and health expenditure was 1805.1 JD per capita. The number of physicians in the same year rose to 13727 , dentists 4597 , pharmacists 6722, registered nurses 9578 and midwives 1595.

Jordan's health system is a complex amalgam of three major sectors: Public, private, and donors. The public sector consists of two major public programs that finance as well as deliver care: the Ministry of Health (MOH) and Royal Medical Services.

The quality of service plays vital role in designing and marketing the service because of its importance for both of service provider and consumer. The awareness among organizations has increased regarding the importance of quality in achieving competitive advantage and became the main subject for possession and attention in recent years. The themes of quality and related issues captured the attention of many businessmen who have become more aware and concern about it (Kotler \& Keller, 2009).

The importance of quality of service has increased on a basis for excelling in the face of competitors. The outstanding service became the criteria of preference among organizations because of similarity in offers 
provided by them to consumers in all services. Thus, the level of quality of service performance became a strong competitive advantage in achieving sustainability and growth among organizations. There are several reasons that call attention for providing quality service to consumers in certain organization whatsoever, including achieving a unique competitive advantage better than the rest of the organizations and decreasing the costs of service due to fewer errors. On the other hand, the distinguished service offers the opportunity to provide service with competitive prices.

The quality of service means the capacity of the service to achieve satisfaction to recipient of the service compared to available alternatives by others (Bojanic, 1991), where the service quality represents the gap between the level of service received by the individual and the level of his expectations. The quality of service appears within three possibilities: negative mistrust (where performance is below the level of expectations), positive mistrust (where performance is above expectations) and confidence (where the performance is equal to what is expected) (Prakash, 1984). The quality of service also means "quality of services provided whether expected or perceived that is expected by the customer or being recognized in real practice and the main determinant for it the satisfaction or dissatisfaction among service recipients" (Babakus \& Boller, 1992).

The importance of measuring the quality of service represents by giving service providers the freedom to act in the workplace in order to achieve satisfaction and happiness among service recipients, setting high measuring standards for the level of service that can be delivered to the recipients, following up and monitoring performance continuously, and providing employees feedback about their closeness or farness from achieving the standard of the service quality (Cronin \& Taylor, 1992).

The importance of the healthcare sector comes from the fact that when you have a good health service in one place, people are not worried about their children's or their own health and hence are able to work better and be more productive (MOH, 2006a). In Jordan, the public sector was formerly the main provider of health services whereas the role of the private sector was limited. Subsequently, due to governmental privatization policies and the national health strategy, the private sector was encouraged to enter the health field. Now the participation of the private sector in providing health services to Jordanians has increased to reach 56 hospitals in 2006. Many private hospitals have been established, creating a competitive environment in terms of service, quality and charges in addition to their social role in the community (MOH, 2006b). This strategy aims to improve and promote the health of all Jordanian citizens by providing them with an efficient and effective health care system.

Jordanian hospitals sought to achieve its goals and future vision through the provision of patient needs and expectations within high quality and competitive prices, especially in the presence of highly competition, both in the internal environment or external, especially at the local and regional levels. So the problem of this study is to assess the quality of health care services in the Hashemite Kingdom of Jordan, by answering the following questions:

- What is the level of health services quality provided to patients in the Hashemite Kingdom of Jordan?

- Are there differences in service's quality provided to patients regarding demographic variables (gender, age, and social status)?

- Are there differences in service's quality provided to patients regarding region variable (center, south, and north)?

\section{Importance of the Study}

The importance of this study stems from providing information to stakeholders in Jordanian hospitals that may contribute in the provision of health services for patients with high quality and competitive prices. As this study reveals the level of health service quality provided to patients of those hospital. Thus, the study may contribute in manifesting the scope of success among Jordanian hospitals to achieve its goals and future vision. Furthermore, the study may contribute in activating the role of health sector in the national economy, and strengthening the position of Jordan.

\section{Theoretical Framework}

\subsection{Service quality definition}

Goetsch \& David (2007) defined the quality as: a case associated with the goods and services, people and processes that meet the wishes and expectations of consumers and even beyond. Also defined by Juran \& Frank (1933) as: fitness for use, and has known by Crosby as: conforming to the requirements (Hicks, 1994). The American Society for Quality Control (ASQC) identified the quality in 1983 as: the characteristics of goods and services that enable them to satisfy the implied needs of consumers, and the lack of deficit in the ability of goods and services to satisfy the needs and desires (Summers, 2009). 
It's obvious from the past definitions the existence of clear differences in the definition of quality with a common features between these definitions the most important of them appears as: that quality is the best performance of the product or service based on user or client, and that quality means the match of good or service with standards and specifications, and quality means a production of good or providing service rightly from the first time, and that the quality is measurable in precisely quantitative manner.

However, the service is defined as: non concrete performance provided by one party to another without resulting in ownership of something. It is noted that this definition includes services provided by insurance companies, banks, transport companies, hospitals, schools, offices, lawyers, doctors, accountants and public utilities such as electricity and water. A variation among researchers appeared regarding organizations that works for sale, whether commodities or services. Some considers what restaurants sell are commodities being provided by something tangible, while others believe that what provided by restaurants are services. So it was necessary to determine the appropriate standard for separating between the two points of view. This criterion is represented in what is bought by the consumer regardless of what accompanied by the purchase of accessories and appurtenants. That means if the satisfaction of the need and meets the requirements in non concrete manner forms the significant deal, then what is purchased by the consumer is a service. However, if the larger deal is to satisfy the need in a concrete manner, then what purchased by the consumer is a commodity (Kotler \& Keller, 2009).

The quality of service is known as: the quality, which includes two dimensions; the first is procedural and related to specific systems and procedures established to provide the service, while the second is a personal and related to the interaction between the workers -with their attitudes and behaviors and verbal practices- and between the customer. It is also known as: the quality of services provided, whether expected or perceived by customers, and is the main determinant of customer satisfaction or dissatisfaction (Summers, 2009).

It is noted from the previous definitions that the quality of service represents the interaction between the service provider and the client. It reflects the level of services provided, whether expected or perceived and received by the client, and become the main determinant of customer satisfaction or dissatisfaction where the client can find the quality of the service through the comparison between expectations and the actual performance of service.

\subsection{Gap theory to measure the service quality}

This approach emerged during the eighties through the studies carried out by Parasuraman; Zeilhmal \& Berry (1998) in order to implement iy in identifying and analyzing the sources of quality and assisting in how to improve them and is known as (SERVQUAL). The assessment of quality according to gap model means identifying the gap between customers expectations for the level of service and their perceptions of actual performance, which means how to identify and determine the scope of concordance between the expected service and perceived service (Zeithaml; Berry \& Parasuraman, 1996).

This approach relies on the measurement of the quality of service on the basis of the analysis and interpretation of psychological operations in which a customer evaluates and judged the quality of services. The difference between expectations and actual perceptions among customers determines the level of service quality. Therefore, the quality of service is determined by the difference between the expected service and perceived service (actual Performance), and therefore the level of service is measured by the congruence between the level of service already provided and what customers expect. In order to reach a good level of service, it is a must to keep pace with customer expectations and cope with it continuously. The quality of perceived service moving in the range between ideal quality and acceptable quality. Consequently, the customers' perception for the quality of service depends on the nature and scope of the discrepancy between expected service and perceived service. Therefore, the quality of service is measured as follows (Zeithaml, \& Bitner, 1996):

- If the expected service is greater than the perceived service (actual performance), the quality of service is less than satisfactory, so the customers will generate a level of non-acceptance.

- If the of expected service equal to the perceived service, the quality of service is satisfactory, and thus there is a level of acceptance among customers.

- If the expected service is less than the perceived service, the quality of the service will be more than satisfactory, and are moving toward the ideal quality, this will continue to a limited extent of time, and will be changeable.

Thus, the main axis in assessing the quality of service according to this model represented in the gap between the client's perception for the actual performance level of the service and his expectations toward it and that gap depends on the nature of the gaps related to designing, marketing and delivering the service, and these gaps are (Summers, 2009; Foster, 2009): 
- Gap I: Customer Expectations - Management Perceptions Gap. It is related to the lack of matching between the specifications of the service with management perceptions for customer expectations. In spite of the recognition of organization's administration for the expectations of the customer, it is not able to translate that into certain specifications in the service provided.

- Gap II: Management Perceptions - Service Quality Specifications Gap. The gap is between the service standards established and the actual performance. If the organization set the required specifications in the service, it cannot perform this service because the specifications are complex and inflexible, and lack of trained personnel in the performance or lack of conviction toward required specifications, or lack of sufficient incentive to perform this service.

- Gap III: Service Quality Specifications - Service Delivery Gap. It is a gap between the desired service and the provided service. The promises given through the promotional activities do not correspond with the actual performance of the service because there are weaknesses in coordination between operations and the outside marketing of the service organization.

- Gap IV: Service Delivery - External Communications Gap. It relates to the gap between expected service and the performed service and this means that the expected service does not match the perceived service as a result of all the gaps so that the judgment on the service organization's performance quality will be based on it.

- Gap V: Expected Service - Perceived Service Gap (or the Service Performance Gap). This gap is the result of the other gaps, and it represents the customer notices.

\subsection{Dimensions of service quality}

Since organizations seek for providing services fit with customer's expectations and meet their needs, it must look for ways and means to develop and improve service quality. Good service from the customer point of view is consistent with their expectations so that the organization must recognize the standards and indicators on which customers judge the quality of service provided to them. The most important indicators or dimensions on which counted to assess the quality of service represented as follows (Kotler \& Keller, 2009; Summers, 2009; Foster, 2009):

1) Reliability: the ability to provide a service to be, as promised, by the organization. That is, more reliable and has a high degree of authenticity and accuracy. The customer is expected to receive a service accurately in terms of commitment with time and performance, and as promised, by the organization. In addition to his reliance on the service provider in the performance.

2) Availability: it relates to the ability of the organization to try providing service at the time that the client wants, and availability where he wants it, in addition to receiving the service when requested, as well as the waiting time of the customer for receiving the service and the accessibility to the place of service delivery.

3) Assurance: it reflects the degree of safe feeling toward provided service and who provide it. It is about the extent of perceived risk resulting from receiving the service from the organization, or from the provider or both.

4) Empathy: (The degree of understanding of the service provider to the needs of the client), it represents the extent to which the service provider can understand customer's needs, identify and provide him with care and attention, and reflect how much time and effort needed by the service provider to identify the needs of the customer and understand his feelings and sympathize with him.

5) Responsiveness: the ability of the service provider to get ready for providing the service to the client on a permanent basis, and his ability to provide service in the time needed by the client, along with a sense of the service provider with enthusiasm and happiness when providing service to the customer and his readiness to do so.

6) Efficacy: it concerns the efficiency and reliability of service providers in terms of their skills and abilities of analysis and reasoning and knowledge that enable them to perform their job well. The customer usually resorts to the education and sources, and scientific expertise to deal with service providers because he would prefer to receive the service of persons with high educational levels and sources of officially approved.

7) Tangible: this refers to the physical facilities available at the organization of service such as: equipment, appearance of service providers, tools and means of contact with them. In many cases, the client turns to judge the quality of the service through formal qualities associated with the service like payments facilities, the technology used in providing the service, the internal appearance and internal and external design of organization to create a comfortable atmosphere for the client.

8) Communication: It relates to the ability of the service provider to explain the characteristics of the service for the client, and the role to be played by the customer for the service required. the client must be informed 
with what he should do, and explain the damage that can cause it if he does not comply with his request, and the problems that can be occurred during service delivery and how to avoid them. So that the process of contacting customer must be clear depending on the appropriate ways and depending on the level and the culture of the client and make sure that the message arrives understandably and clearly.

\section{Methodology}

\subsection{Population and sample of the study}

The population of this study consisted of patients admitted in all Jordanian hospitals located in the north, center and south. Three main hospitals located in different three regions were chosen. The hospitals are: King Abdullah hospital, Al Bashir Hospital and Al Karak Hospital. Then, the sample was selected in July 2010 from patients of these hospitals. The instruments of the study were distributed on them. The number of distributed questionnaires reached to (657) where (589) of them were taken back and (33) ruled out because of non-validity for analysis. Thus, the total number of valid questionnaires for analysis became (556). Table (1) shows characteristics of the study sample.

Insert Table 1- here

\subsection{Measure of service quality}

To achieve the purpose of this study a scale was develop in order to measure the quality of health service provided to patients of Jordanian hospital. The scale was developed to measure the quality of service within five dimensions: Tangibles, reliability, responsiveness, assurance and empathy (Parasuraman \& Zeithaml \& Berry, 1988). The scale based on a comparison of customer's expectations and their perceptions for the actual service provided to them using the five dimensions of quality aspects, and thus the level of quality service is detect through recognizing the scope of concordance between customer expectations for service and its actual performance. The quality of the service represents the gap between expectation and perception or may be a gap between customer expectations of service quality and perception of management for those expectations, or represents the gap between the specifications of the service actually provided and the management perception of customer's expectations, or the gap between management perception for standards of quality and service actually provided - also called the performance gap - or the gap caused by the imbalance in the credibility of the Organization that appears through communication with customers, which is already different from the level of service and it's standards. Moreover, it represents the gap between the service performed and expected, and thus the quality of service achieves customer's satisfaction (Murfin, et al., 1995). Accordingly, the main objective of the scale of service quality (SERVQUAL) is to clarify the series of gaps that perception of the patients are affected for the quality of health services and make them desirable. The related scales of (SERVQUAL) implemented in previous studies as (Akbaba, 2006) and (Hsieh; Lin, \& Lin, 2008) were revised.

The developed scale consisted of (31) items distributed on five dimensions: Tangibles, reliability, responsiveness, assurance and empathy. Table (2) shows the distribution of items on the five dimensions. A five-point Likert type scale was counted on for determining the responses on items by members of the sample. The answers on the scale distributed on five degrees for (strongly agree), four degrees for (agree), three degrees for (nor), two degrees for (disagree) and one degree for (strongly disagree). The graduation of the scale relies on standard divided into three equal categories. The cut-off point was calculated by dividing the difference between the highest value and the minimum value on three degrees that represents the number of levels $([5-1] / 3=1.33)$. Thus, the three resulted levels are: (3.68-5) high, (2.34-3.67) average, (1-2.33) low.

Insert Table 2- here

\subsubsection{Validity}

\subsubsection{Face Validity}

The scale of service quality was introduced to five arbitrators who are professors in administration at Al-Balqa Applied University and University of Jordan in order to find out the following: suitability of the items of the scale with the dimension that are intended to measure, the extent of fitness in language diction, and the extent of scale adaptation with the Jordanian environment. The observations, opinions and suggestions of the arbitrators were taken in consideration through reformulating of some items without eliminating any item.

\subsubsection{Construct Validity}

To confirm the construct validity of the scale an Exploratory Factor Analysis EFA was performed. The factor structure for the instrument was examined with principal axis factoring analysis to explain as much of the correlation among the variables and minimum number of factors with oblique rotation, which allows the factors 
to correlate. Conway and Huffcutt (2003) agreed with Ford, MacCallum \& Tait (1986) that an oblique rotation was preferred, based on eigenvalue greater than (1.0) scree plot. Regarding to decisions made by researchers, Ford et al. (1986) found that the most common technique reported was retaining factors with eigenvalue greater than 1 (Conway and Huffcutt, 2003).

Table (3) shows that there are five factors, each with an eigenvalue close to (1.0) (Kaiser, 1960) which interprets $58.645 \%$ of the variation among individuals responses in the study sample on the quality dimensions. The table also shows that the interpreted variance percentage of the first factor was high at (27.615). We can also see that the eigenvalue was relatively high at (8.561) compared with other factors whose eigenvalue were closer and smaller. It can also be noted that the item loadings of the quality dimensions on the five factors were high, as the correlation coefficient among the items of each factor, and the factor that it represents is more than $(0.30)$.

Insert Table 3- here

\subsubsection{Reliability}

For the estimates of reliability, coefficient of internal consistency was performed for the scale. The responses of the study sample were examined, (556) individuals, using Cronbach's Alpha coefficient. The exploratory alpha coefficients ranged from 0.83 to 0.92 which indicates that the values have shown acceptable levels of reliability based on the criterion of Nunnally (1978). Table (4) shows the results.

\section{Insert Table 4- here}

\subsection{Analytical procedure}

Statistical packages for the Social Sciences (SPSS) were performed in order to achieve a descriptive analysis of the study and testing of hypotheses. Frequencies and percentages were used to identify the characteristics of the study sample. The means and standard deviations were used to answer the study questions. The analysis of variance and Scheffe test were used to test hypotheses.

\section{Results}

It is noted from table (5) that the level of quality of health services provided to patients of Jordanian hospitals is moderate $(\mathrm{M}=3.49, \mathrm{SD}=0.43)$, and the dimensions of service quality are mediums except (responsiveness, assurance) which were high. An analysis of the dimensions of service quality clears that responsiveness occupied the first rank $(\mathrm{M}=3.78)$, followed by Assurance which came at the second rank $\mathrm{M}=3.74$, followed by Tangibles which came at the third rank $(M=3.57)$, followed by Empathy which came at the fourth rank $(M=3.36)$, while reliability came at the last ranks $(M=2.98)$. The table also shows a significant correlation between all dimensions of quality of service.

\section{Insert Table 5- here}

Notes from table (6) shows no significant differences in the level of quality health services provided to patients of Jordanian hospitals regarding social status variable, $(f=0.40)$, non- significant at $(\alpha=0.05 ; 0.01)$. Build on these results the acceptance of the null hypothesis, "There is no significant differences at $(\alpha=0.05,0.01)$ in the level of quality health services provided to patients of Jordanian hospitals regarding social status variable."

The results indicate also that there were significant differences in the level of quality health services provided to patients of Jordanian hospitals regarding (gender, age, region) variables, (f) for gender (9.06), for age (3.76) and for region (10.36), which are significant at the level of $(\alpha=0.05,0.01)$. Based on these results, the rejection of alternative hypothesis, "There are no significant differences at $(\alpha \leq 0.05)$ in the level quality of health services provided to patients of Jordanian hospitals regarding (gender, age, region) variables."

\section{Insert Table 6- here}

The differences in the level of quality health services provided to patients of Jordanian hospitals regarding gender variable become significant for females. To determine the direction of differences related to (age, region) variables, Scheffe test was used for a posteriori comparisons. Table (7) shows test results which indicate the existence of differences in the level of quality health services provided to patients of Jordanian hospitals among the patients, who ranged in age between (46-55 years) and patients who were aged more than 55 years where the level of quality service provided to patients who were aged more than 55 years was better. The table also indicates the existence of differences in the level quality of health services provided to patients of Jordanian hospitals among patients in the north and south regions where the level of service quality was better in the north region.

\section{Insert Table 7- here}




\section{Conclusion}

The study results showed that the level of quality of health services provided to patients of Jordanian hospitals is moderate while the dimensions of the service quality mediums except (responsiveness, assurance) were high. According to the analysis of the dimensions of service quality it is clear that responsiveness occupied the first rank, followed by assurance which came at the second rank, followed by tangibility which came at the third rank, followed by Empathy that came at the fourth rank, while reliability ranked lastly. The results also present a significant correlation between all dimensions of quality of service. This result indicates a gap between the expectations of the patient services provided to him in Jordanian hospitals and what is perceived actually that may related to the variation of diseases among patients which leads to differences in their needs and expectations. From another point of view, this result can be interpreted regarding the level of hospitals managers understanding and their perception for the needs and expectations of patients which are not at the required level. With regard to achieving the first rank by responsiveness, it was due to the increasing in the capacity of the service provider in the hospital and its readiness to provide health service for patients on a permanent basis, in addition to its ability to provide health service in the needed time for the patient. The lowest rank for reliability may be related to non providing health services by hospitals as patients were promised so that patient expectations toward the level of service did not match with the level of health service actually provided to him.

These findings was consistent with the findings of Abd-Al Halim and Shalabi (2001) study which showed an average level for the following dimensions examined in public hospitals: the suitability of site's buildings, public hospitals requirements, the efficiency and qualifying of the stuff working in, the adequacy of medical equipments, the efficiency of laboratories and it's assays, the appropriateness of pharmacies services, the availability of drugs and their effectiveness and finally the impact of administrative procedures and routines. The findings of this study agreed well with the results of Al Assaf (2006) study which showed that the overall average attitudes of the outpatients' clinics in private hospital were positive. The current findings differs with the results of Hayajna (2008) study which indicated an existence of variation in the attitudes among study sample regarding the quality of the service where tangibility dimension came at first rank, followed respectively by safety, merit, reliability, responsiveness, credibility, and communication which came lastly.

The results of current study revealed no significant differences in the level of quality health services provided to patients of Jordanian hospitals regarding the social status variable. While the results indicated the presence of significant differences in the level of quality health services provided to patients of Jordanian hospitals regarding (gender, age, region) variables, where the differences for the gender variable are significant for females. Differences were found in the level of quality health services provided to patients of Jordanian hospitals among patients their ages ranged between (46-55 years) and patients who were aged more than 55 years where the level of quality service provided to them was better. The differences in the level of quality health services provided to patients of Jordanian hospitals were found among patients in the regions of north and south where the level was better in the north region.

\section{Recommendations}

In light of the results revealed in current study, it continue to add a range of recommendations aimed at enhancing the assessment of quality health services provided to patients of Jordanian hospitals, and these recommendations are:

- Enhancing the quality of health services provided to patients of Jordanian hospitals, particularly in the southern region, in particular, through concerning to achieve the dimensions of tangibility, empathy, and reliability in the health service, according to the expectations of patients.

- The necessity of hospital managers to concern and understand the needs and expectations of patients, and taking into account the levels of their ages and their future needs.

- Selection and recruitment of persons who are scientifically and practically qualified, especially in the field of health administration. Furthermore, training employees on the art of dealing with others according to their traits, patterns of their personalities and their psychological states.

- Conducting further prospective studies related to the health sector, especially comparative studies between public, private and military sectors.

\section{References}

Abd-Al Halim, Ahmed., \& Shalabi, Faisal Marei. (2001). The level of health services provided in government hospitals in Jordan: an assessment from the viewpoint of physicians working therein. Mutah for Research and Studies, 17(6), 77-117. 
Akbaba Atilla. (2006). Measuring Service Quality in the Hotel Industry: A Study in A Business Hotel in Turkey. Hospitality Management, 25, 170-192. http://dx.doi.org/10.1016/j.ijhm.2005.08.006

Al-Assaf, Majd. (2006). Trends of patient about the quality of outpatient services in public and private hospitals in Amman. Unpublished Master Thesis, University of Jordan.

American Society for Quality Control. (1983). ASQC Glossary and Tables for Statistical. Quality Control, 230 W. Wells Street, Milwaukee, Wisconsin 53203.

Babakus, E., \& Boller, G. W. (1992). An empirical assessment of the SERVQUAL Scale. Journal of Business Research, 24(3), 253-268. http://dx.doi.org/10.1016/0148-2963(92)90022-4

Bojanic, David, C. (1991). Quality Measurement in Professional Services Firms. Journal of Professional Services Marketing, 7(2), 27-36. http://dx.doi.org/10.1300/J090v07n02_04

Conway, James., \& Huffcutt, A. I. (2003). A Review and Evaluation of Exploratory Factor Analysis Practices in Organizational Research. Organizational Research Methods, 6(1), 147. http://dx.doi.org/10.1177/1094428103251541

Cronin, Joseph., \& Taylor, Steven. (1992). Measuring Service Quality: Reexamination and Extension. Journal of Marketing, 56(3), 55-68. http://dx.doi.org/10.2307/1252296

Ford, J. K., Maccallum, R. C., \& Tait, M. (1986). The Application of Exploratory Factor Analysis in Applied Psychology: A Critical Review and Analysis. Personnel Psychology, 39, 291-314. http://dx.doi.org/10.1111/j.1744-6570.1986.tb00583.x

Foster, S. Thomas. (2009). Managing Quality: Integrating the Supply Chain. (4th ed.). New Jersey: Prentice-Hall.

Goetsch, David L., \& David Stanly. (2007). Quality Management: Introduction to Total Quality Management for Production, Processing, and Services, (4th ed.). New Jersey: Prentice Hall International Inc.

Hayajna, Omar. (2008). The effect of service quality on customers satisfaction of the Jordan telecom group. Unpublished Master Thesis, University of Al al-Bayt: Mafraq, Jordan.

Hicks, Philip E. (1994). Industrial Organizational and Management: A new Perspective, (2nd ed.). Singapora: Mc Grow - Hill. Inc.

Hsieh, Ling-Feng., Lin, Li-Hung., \& Lin, Yi-Yin. (2008). A Service Quality Measurement Architecture for Hot Spring Hotels in Taiwan. Tourism Management, 29, 429-438. http://dx.doi.org/10.1016/j.tourman.2007.05.009

Juran, J. M., \& Frank M. Gryna (1993). Quality Planning and Analysis, (3rd ed.). N.Y.: McGrow - Hill, Inc.

Kaiser, H. F. (1960). The Application of Electronic Computers to Factor Analysis. Educational and Psychological Measurement, 20, 141-151. http://dx.doi.org/10.1177/001316446002000116

Kotler, Ph., \& Keller, K. L. (2009). Marketing Management. (13th Ed.).New Jersey: Pearson Prentice Hall.

Ministry of Health (2006a). National Health Strategy. Jordan: Ministry of Health.

Ministry of Health (2006b). Directorate of Information Studies and Research. Annual Statistical Book. Jordan: Ministry of Health.

Murfin, D. E., Schlegelrmilch, B. B., \& Diamantopoulos, A. (1995). Perceived Service Quality and Medical Outcome: An Interdisciplinary Review and Suggestions for Future Research. Journal of Marketing Management, 11, 97-117. http://dx.doi.org/10.1080/0267257X.1995.9964332

Nunnally, J. C. (1978). Psychometric Theory. (2nd ed.). New York: McGraw-Hill.

Parasuraman, A., Zeithaml, V. A., \& Berry, L. L. (1998). SERVOQUAL: A Multiple-Item Scale for Measuring Customer: Perceptions of Service Quality. Journal of Reading, 64(Spring), 12-40.

Prakash, Ved. (1984). Validity and Reliability of the conformation of Expectations Paradigms as a Determinant of Consumer Satisfaction. Journal of the Academy of Marketing Science, 12(4), 63-76. http://dx.doi.org/10.1007/BF02721800

Summers, Donna. (2009). Quality. (5th ed.). New Jersey: Prentice-Hall Inc.

Zeithaml, V. A., \& Bitner, M. J. (1996). Services Marketing. New York: McGraw-Hill. 
Table 1. Characteristics of the study sample

\begin{tabular}{|c|c|c|c|}
\hline $\begin{array}{c}\text { Demographic } \\
\text { Variables }\end{array}$ & level & $\mathrm{N}$ & $\%$ \\
\hline Gender & Male & 359 & 64.6 \\
\hline & Female & 197 & 35.4 \\
\hline Age & Less than 25 & 64 & 11.5 \\
\hline & $25-35$ & 132 & 23.7 \\
\hline & $36-45$ & 164 & 29.5 \\
\hline Social status & $46-55$ & 97 & 17.4 \\
\hline & More than 55 & 99 & 17.8 \\
\hline Region & Singl & 155 & 27.9 \\
\hline & Married & 401 & 72.1 \\
\hline & Center & 250 & 45.0 \\
\hline & South & 139 & 25.0 \\
\hline
\end{tabular}

Table 2. The distribution of scale items on quality service dimensions

\begin{tabular}{|c|c|c|c|}
\hline No. & $\begin{array}{c}\text { Service quality } \\
\text { dimentions }\end{array}$ & Items No. & Items \\
\hline 1 & Tangibles & $1-10$ & 10 \\
\hline 2 & Reliability & $11-15$ & 5 \\
\hline 3 & Responsiveness & $16-19$ & 4 \\
\hline 4 & Assurance & $20-24$ & 5 \\
\hline 5 & Empathy & $25-31$ & 7 \\
\hline- & Total & - & 31 \\
\hline
\end{tabular}


Table 3. Factor Analysis for SEVQAUL Items and Their Loadings

\begin{tabular}{|c|c|c|c|c|c|}
\hline \multirow[t]{2}{*}{ SEVQAUL items } & Factor 1 & Factor 2 & Factor 3 & Factor 4 & Factor 5 \\
\hline & Tangibles & Empathy & Assurance & Responsiveness & Reliability \\
\hline Q2 & 0.781 & & & & \\
\hline Q7 & 0.771 & & & & \\
\hline Q3 & 0.700 & & & & \\
\hline Q6 & 0.700 & & & & \\
\hline Q9 & 0.697 & & & & \\
\hline $\mathrm{Q} 4$ & 0.683 & & & & \\
\hline Q5 & 0.659 & & & & \\
\hline Q1 & 0.658 & & & & \\
\hline Q10 & 0.653 & & & & \\
\hline Q8 & 0.614 & & & & \\
\hline Q30 & & 0.817 & & & \\
\hline Q29 & & 0.782 & & & \\
\hline Q28 & & 0.722 & & & \\
\hline Q31 & & 0.686 & & & \\
\hline Q26 & & 0.681 & & & \\
\hline Q27 & & 0.661 & & & \\
\hline Q25 & & 0.655 & & & \\
\hline Q24 & & & 0.773 & & \\
\hline Q23 & & & 0.759 & & \\
\hline Q22 & & & 0.720 & & \\
\hline Q21 & & & 0.703 & & \\
\hline Q20 & & & 0.668 & & \\
\hline Q17 & & & & 0.850 & \\
\hline Q19 & & & & 0.845 & \\
\hline Q18 & & & & 0.820 & \\
\hline Q16 & & & & 0.706 & \\
\hline Q15 & & & & & 0.791 \\
\hline Q14 & & & & & 0.742 \\
\hline Q12 & & & & & 0.714 \\
\hline Q13 & & & & & 0.512 \\
\hline Q11 & & & & & 0.499 \\
\hline Eigenvalue & 8.561 & 3.677 & 2.155 & 2.089 & 1.698 \\
\hline Percentage of variance & 27.615 & 11.861 & 6.953 & 6.738 & 5.479 \\
\hline $\begin{array}{l}\text { Cumulative percentage } \\
\text { of variance }\end{array}$ & 27.615 & 39.475 & 46.428 & 53.167 & 58.645 \\
\hline
\end{tabular}

Table 4. Coefficient of internal consistency of the dimensions of service quality scale

\begin{tabular}{|c|c|c|}
\hline No. & $\begin{array}{l}\text { Service Quality } \\
\text { Dimensions }\end{array}$ & Coefficient \\
\hline 1 & Tangibles & 0.92 \\
\hline 2 & Reliability & 0.88 \\
\hline 3 & Responsiveness & 0.83 \\
\hline 4 & Assurance & 0.86 \\
\hline 5 & Empathy & 0.87 \\
\hline
\end{tabular}


Table 5. Means, standard deviations, correlation coefficient of the quality health services provided to hospital patients of Jordan

\begin{tabular}{|c|c|c|c|c|c|c|c|c|c|c|}
\hline No. & $\begin{array}{c}\text { Service Quality } \\
\text { Dimensions }\end{array}$ & Mean & S.D. & Rank & Level & Tan. & Rel. & Res. & Ass. & Emp. \\
\hline 1 & Tangibles & 3.57 & 0.63 & 3 & Medium & - & & & & \\
\hline 2 & Reliability & 2.98 & 0.65 & 5 & Medium & $0.49 * *$ & - & & & \\
\hline 3 & Responsiveness & 3.78 & 0.78 & 1 & High & $0.48 * *$ & $0.31 * *$ & - & & \\
\hline 4 & Assurance & 3.74 & 0.63 & 2 & High & $0.48 * *$ & $0.39 * *$ & $0.37 * *$ & - & \\
\hline 5 & Empathy & 3.36 & 0.71 & 4 & Medium & $0.45 * *$ & $0.32 * *$ & $0.33 * *$ & $0.34 * *$ & - \\
\hline- & Total & 3.48 & 0.43 & - & Medium & $0.83 * *$ & $0.63 * *$ & $0.64 * *$ & $0.66^{* *}$ & $0.41 * *$ \\
\hline
\end{tabular}

Table 6. Analyze of variance to the differences in quality health services provided to hospital patients of Jordan due to (gender, age, marital status, region) variables

\begin{tabular}{|c|c|c|c|c|}
\hline Demographic Variables & level & Mean & S.D. & $\mathrm{F}$ \\
\hline \multirow[t]{2}{*}{ Gender } & Male & 3.44 & 0.45 & $9.06^{* *}$ \\
\hline & Female & 3.56 & 0.38 & \\
\hline \multirow[t]{5}{*}{ Age } & Less than 25 & 3.50 & 0.28 & $3.76^{*}$ \\
\hline & $25-35$ & 3.48 & 0.50 & \\
\hline & $36-45$ & 3.47 & 0.37 & \\
\hline & $46-55$ & 3.37 & 0.53 & \\
\hline & More than 55 & 3.61 & 0.37 & \\
\hline \multirow[t]{2}{*}{ Social status } & Singl & 3.50 & 0.38 & 0.40 \\
\hline & Married & 3.48 & 0.45 & \\
\hline \multirow[t]{3}{*}{ Region } & Center & 3.42 & 0.48 & $10.36^{* *}$ \\
\hline & South & 3.46 & 0.34 & \\
\hline & North & 3.61 & 0.41 & \\
\hline $\begin{array}{l}* * \mathrm{P} \text {-value is } \mathrm{s} \\
* \mathrm{P} \text {-value is } \mathrm{s}\end{array}$ & $\begin{array}{l}\text { at the } 0.01 \mathrm{lev} \\
\text { at the } 0.05 \mathrm{lev}\end{array}$ & & & \\
\hline
\end{tabular}

Table 7. Scheffe results for the differences in the quality health services provided to hospital patients of Jordan due to (age, region) variables

\begin{tabular}{|c|c|c|c|c|c|c|}
\hline Demographic Variables & Level & Mean & $\begin{array}{c}\text { Less than } \\
25\end{array}$ & $25-35$ & $36-45$ & $46-55$ \\
\hline Age & Less than 25 & 3.50 & - & & & \\
\hline & $25-35$ & 3.48 & 0.02 & - & & \\
\hline & $36-45$ & 3.47 & 0.03 & 0.01 & - & \\
\hline & $46-55$ & 3.37 & 0.13 & 0.11 & 0.10 & - \\
\hline & More than 55 & 3.61 & 0.11 & 0.13 & 0.14 & $0.24^{* *}$ \\
\hline & & Mean & Mid & South & North & \\
\hline & Center & 3.42 & - & & & \\
\hline & South & 3.46 & 0.04 & - & & \\
\hline Region & North & 3.61 & $0.19^{* *}$ & $0.15^{* *}$ & - & \\
\hline & \multicolumn{7}{l}{} \\
\hline
\end{tabular}

